\title{
Perfil lipídico sérico de ratos tratados com surfactante
}

\author{
Serum lipid levels of rats treated with surfactant
}

\author{
Karina Ferreira de CASTRO ${ }^{1}$; Silvana Martinez Baraldi ARTONI ${ }^{2}$; Maria Rita PACHECO $^{2}$
}

${ }^{1}$ Pós Graduanda em Clínica Médica Veterinária daUniversidade Estadual Paulista Júlio de Mesquita Filho, Jaboticabal-SP, Brasil ${ }^{2}$ Departamento de Morfologia e Fisiologia Animal daUniversidade Estadual Paulista Júlio de Mesquita Filho, , Jaboticabal-SP, Brasil

\begin{abstract}
Resumo
A aterosclerose é uma doença multifatorial, lenta e progressiva e a hiperlipidemia um dos fatores potenciais no desenvolvimento de doenças cardíacas ateroscleróticas. As vantagens da indução das dislipidemias experimentais são a produção de lesões ateromatosas em curto espaço de tempo; adequado controle dietético e fatores ambientais; a possibilidade de estudos sobre a reversibilidade de lesões ateroscleróticas e ensaios pré-clínicos de substâncias hipolipidêmicas. Este estudo visou avaliar o perfil lipídico sérico de ratos tratados com surfactante. Foram utilizados 28 ratos Wistar, machos, albinos, adultos e hígidos. Estes foram distribuídos em quatro grupos experimentais formados por sete animais cada, a saber: Grupo I - (controle); Grupo II - tratado com tyloxapol, na dose de $500 \mathrm{mg} / \mathrm{kg}$ de peso corporal, via intraperitoneal a cada 48 horas, durante duas semanas; Grupo III - tratado com tyloxapol na dose de 500 $\mathrm{mg} / \mathrm{kg}$ de peso corporal, via intraperitoneal a cada 48 horas, durante três semanas; Grupo IV - tratado com tyloxapol na dose de $500 \mathrm{mg} / \mathrm{kg}$ de peso corporal, via intraperitoneal a cada 48 horas, durante quatro semanas. Na avaliação do perfil lipídico, os valores de triacilgliceróis e HDL demonstraram que o grupo III diferiu significativamente do grupo I e os valores de colesterol total e LDL indicaram que o grupo I diferiu significativamente dos grupos II, III e IV. Conclui-se que o surfactante tyloxapol foi efetivo na indução da hiperlipidemia.
\end{abstract}

Palavras-chave: Perfil lipídico.Colesterol.Triacilglicerol. Rato. Surfactante.

\begin{abstract}
Atherosclerosis is a multifactorial, progressive and slow disease, and hyperlipidaemia is one of the potential factors in the development of atherosclerotic cardiac diseases. The experimental dyslipidaemia carrying out advantages are the production of atheromatous lesions in a short period of time, an adequate dietetic control and environmental factors, the possibility of studies concerning reversibility of atherosclerotic lesions, and pre-clinic experiments with hypolipidaemic substances. This study aims at evaluating tyloxapol analyzing serum lipid levels. Twenty-eight healthy Wistar adults' albino male rats, weighing an average of $200 \mathrm{~g}$ were utilized. They were distributed into four experimental groups with seven animals each, as follows: Group I - (control); Group II - treated with tyloxapol at a dose of $500 \mathrm{mg} / \mathrm{kg}$ of body weight, through intraperitoneal via each 48 hours, for two weeks; Group III - treated with tyloxapol at a dose of 500mg/ $\mathrm{kg}$ of body weight, through intraperitoneal via each 48 hours, for three weeks; Group IV - treated with tyloxapol at a dose of $500 \mathrm{mg} / \mathrm{kg}$ of body weight, through intraperitoneal via each 48 hours, for four weeks. As lipid profile evaluation is concerned, the values of triacylglycerols and HDL have indicated that group III has significantly differed from group I and the values of total cholesterol and LDL have indicated that group I has significantly differed from group II, III and IV. It was concluded that for the studied period the surfactant tyloxapol was effective to inducing hyperlipidaemia.
\end{abstract}

Keywords: Lipid profile. Cholesterol. Triacylglycerol. Rat. Surfactant.

\section{Introdução}

As doenças do sistema cardiovascular são consideradas as maiores causas de óbito nos países industrializados e, atualmente, está estabelecido que a hiperlipidemia representa um importante fator de risco para o desenvolvimento precoce de aterosclerose e complicações cardiovasculares ${ }^{1,2,3}$.

Durante os últimos trinta anos, houve um declínio razoável da mortalidade por causas cardiovasculares em países desenvolvidos, enquanto elevações rela- tivamente rápidas e substanciais têm ocorrido em países em desenvolvimento, dentre os quais o Brasil. De acordo com as projeções da Organização Mundial de Saúde, esta tendência de elevação na doença car-

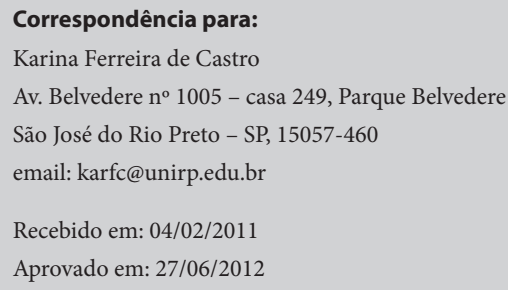


diovascular tende a persistir, agravando ainda mais o quadro de morbidade e mortalidade elevadas nestes países, principalmente decorrente do tabagismo, hipertensão arterial, diabete melito, obesidade e dislipidemias ${ }^{4}$.

Um estudo conduzido em nove capitais brasileiras demonstrou que $38 \%$ dos homens e $42 \%$ das mulheres possuem níveis séricos de colesterol total acima dos valores da normalidade ${ }^{4}$.

Atualmente, estudos dietéticos, metabólicos e toxicológicos são extensivamente realizados na tentativa de elucidar os fatores de risco para hipercolesterolemia e suas consequências patológicas, tais como, lesões no sistema cardiovascular, cérebro, entre outros ${ }^{5}$.

As vantagens da indução das dislipidemias experimentais são a produção de lesões ateromatosas em curto espaço de tempo, adequado controle dietético associado a fatores ambientais, a possibilidade de estudos sobre a reversibilidade de lesões ateroscleróticas e ensaios pré-clínicos de substâncias hipolipidêmicas ${ }^{6}$.

O surfactante tyloxapol, um detergente não iônico, através da sua habilidade em inibir a lipase lipoprotéica (LLP) $)^{7,8}$, induz ao aumento do colesterol e triacilgliceróis séricos, além de favorecer o aumento da atividade da enzima hidroximetilglutaril - CoAredutase (HMG-CoA), que é a enzima-chave intracelular para síntese do colesterol hepático ${ }^{4,5,9,10,11}$. Tem sido amplamente utilizado para bloquear a depuração das lipoproteínas ricas em triacilgliceróis e, assim, induzir a hiperlipidemia aguda em diversos animais ${ }^{2}$.

O modelo experimental de indução de hiperlipidemia com o uso do surfactante é amplamente utilizado para diversos objetivos, tais como, avaliar a eficácia de substâncias naturais ${ }^{12}$ ou sintéticas com efeitos hipolipidêmicos, estudar afecções patológicas que possam ser induzidas pelas dislipidemias, como a pancreatite ${ }^{2,8,11,13,14}$.

A administração intraperitoneal do surfactante na dose de $300 \mathrm{mg} / \mathrm{kg}$ de peso corporal em ratos foi efi- caz na indução da hipercolesterolemia, observando-se um aumento de $108 \%$ nos níveis de triacilgliceróis ${ }^{15}$.

Foi demonstrado que a administração parenteral do surfactante em ratos adultos induziu a hiperlipidemia e os níveis máximos de triacilgliceróis e colesterol total plasmáticos foram alcançados em 20 horas após sua aplicação, seguido por um declínio aos valores normais ${ }^{6}$. Resultados similares foram, posteriormente, obtidos por diversos autores ${ }^{2,6,16,17,18}$.

Outro estudo utilizando uma única injeção do surfactante na dose de $500 \mathrm{mg} / \mathrm{kg}$ de massa corpórea pela via intravenosa causou lipemia com níveis séricos elevados de colesterol, triacilgliceróis e HDL em ratos necropsiados um ou dois dias após a aplicação. Observou-se que os níveis lipídicos retornaram aos valores de normalidade no terceiro dia após uma única injeção ${ }^{5}$.

Informações semelhantes foram obtidas quando da aplicação de $250 \mathrm{mg} / \mathrm{kg}$ de peso corporal por via intravenosa do mesmo surfactante e realizada mensuração dos níveis de colesterol e triacilgliceróis antes e um, dois e quatro dias após a administração do surfactante. Foram obtidos níveis elevados tanto de colesterol, como de triacilgliceróis, um e dois dias após a injeção do surfactante e os valores retornaram ao normal no quarto dia após a utilização desta substância ${ }^{19}$.

Estudando a qualidade e a durabilidade do estado hipercolesterolêmico induzido pelo tyloxapol na dose de $200 \mathrm{mg} / \mathrm{kg}$, outros pesquisadores concluíram que esta substância foi bastante efetiva na indução de hipercolesterolemia com pico em 72 horas após a administração, contudo, após esse período, houve queda dos níveis de colesterol para valores comparáveis aos basais ${ }^{20}$.

Raramente estudos com o surfactante são conduzidos de forma crônica, devido ao fato dos valores de triacilgliceróis e colesterol retornarem à faixa de normalidade rapidamente após sua administração. Entretanto, obtiveram-se níveis elevados e persistentes de forma ininterrupta dessas substâncias quando o surfactante fora administrado três vezes por semana (segundas, quartas e sextas-feiras) na dose de $500 \mathrm{mg} /$ 
$\mathrm{kg}$ por via intravenosa em ratos, persistindo até três dias após a última injeção. Os níveis de colesterol obtidos neste estudo foram 10 a 20 vezes maiores do que os níveis dos animais controle (normais) ${ }^{5}$.

As doses do surfactante descritas para indução de hiperlipidemia em ratos variam de acordo com os estudos e estão em intervalos de 100 a $600 \mathrm{mg} / \mathrm{kg}$ a partir de uma solução previamente diluída com solução fisiológica a $10 \%$, $5,6,9,10,11,15,16,19,21,22$.

\section{Material e Método}

Para este estudo, foram utilizados 28 ratos Wistar, machos, albinos, adultos com peso médio de $200 \mathrm{~g}$ e hígidos, provenientes do Biotério da Faculdade de Medicina Veterinária e Zootecnia, da Universidade Estadual Paulista (UNESP), Campus de Botucatu - SP. Estes animais foram adaptados em gaiolas no Biotério do Hospital Veterinário "Dr. Halim Atique" do Centro Universitário de Rio Preto (UNIRP), São José do Rio Preto - SP, com temperatura controlada e ciclo de claro-escuro de 12 horas e receberam água e ração para manutenção ad libitum, durante 30 dias consecutivos.

Os animais foram distribuídos em quatro grupos experimentais (Tabela 1), formados por sete animais cada, a saber: Grupo I - (controle), recebeu 1,5 mL de solução fisiológica via intraperitoneal a cada 48 horas, durante quatro semanas consecutivas; Grupo II - tratado com surfactante, na dose de $500 \mathrm{mg} / \mathrm{kg}$ de peso corporal, via intraperitoneal a cada 48 horas, durante duas semanas consecutivas; Grupo III - tratado com surfactante na dose de $500 \mathrm{mg} / \mathrm{kg}$ de peso corporal, via intraperitoneal a cada 48 horas, durante três semanas consecutivas; Grupo IV - tratado com surfactante na dose de $500 \mathrm{mg} / \mathrm{kg}$ de peso corporal, via intraperitoneal a cada 48 horas, durante quatro semanas consecutivas(Tyloxapol - Triton WR 1339 Sigma-Aldrich Biotechnology LP).

Após 48 horas do término dos tempos descritos para cada grupo experimental, os animais foram submetidos a jejum alimentar de 16 horas e, em seguida, foram anestesiados com éter etílico, via inalatória, para a colheita de sangue por punção cardíaca, visando o estudo bioquímico dos níveis séricos de colesterol total, triacilgliceróis, HDL e LDL. Após a colheita de sangue sem anticoagulante, este foi acondicionado em tubos e centrifugado a $1500 \mathrm{G}$, durante $10 \mathrm{minu}$ tos. A amostra de soro obtida foi congelada a $-20^{\circ} \mathrm{C}$ até o momento do processamento. A seguir, os animais foram eutanasiados, mediante o aprofundamento anestésico com o mesmo fármaco.

\section{Avaliação do perfil lipídico sérico}

Após descongelamento, as amostras de soro foram utilizadas para as determinações dos níveis séricos de colesterol total, triacilglicerol, HDL e LDL através de análise semiautomática (Labquest Modelo Bio 2000, Labtest Diagnóstica S.A., Lagoa Santa-MG) no Laboratório de Análises Clínicas do Departamento de Clínica e Cirurgia Veterinária da FCAV, Campus de Jaboticabal, São Paulo. Todas as análises foram feitas em duplicatas.

Os valores médios do perfil lipídico (colesterol, triacilgliceróis, HDL e LDL) foram transformados em

Tabela 1 - Procedimento experimental

\begin{tabular}{|c|c|c|c|c|}
\hline & Grupo I & Grupo II & Grupo III & Grupo IV \\
\hline Número de animais & 7 & 7 & 7 & 7 \\
\hline $\begin{array}{l}\text { Dose/via de administração do } \\
\text { surfactante }\end{array}$ & $\begin{array}{l}500 \mathrm{mg} / \mathrm{kg} \text { de peso corporal } \\
\text { via intraperitoneal }\end{array}$ & $\begin{array}{c}500 \mathrm{mg} / \mathrm{kg} \text { de peso corporal } \\
\text { via intraperitoneal }\end{array}$ & $\begin{array}{l}500 \mathrm{mg} / \mathrm{kg} \text { de peso corporal } \\
\text { via intraperitoneal }\end{array}$ & $\begin{array}{l}500 \mathrm{mg} / \mathrm{kg} \text { de peso corporal } \\
\text { via intraperitoneal }\end{array}$ \\
\hline Intervalo entre aplicações & 48 horas & 48 horas & 48 horas & 48 horas \\
\hline Tempo de duração & 4 semanas & 2 semanas & 3 semanas & 4 semanas \\
\hline
\end{tabular}


log. O procedimento estatístico foi realizado mediante ANOVA para verificar a diferença entre os tratamentos dos grupos I, II, III e IV. No caso das diferenças significativas observadas entre os tratamentos, foi utilizado o teste a posteriori de Tukey para determinar entre quais tratamentos as diferenças ocorreram (comparação das médias). Um valor de $\mathrm{p}<0,05$ foi considerado estatisticamente significativo e as análises foram realizadas no programa estatístico AgroEstat (Sistema para Análises Estatísticas de Ensaios Agronômicos) versão 1.0, 2009.

\section{Resultados}

A análise estatística dos resultados referentes aos valores médios \pm EPM do perfil lipídico sérico em log, obtidos neste estudo, estão expressos nas figuras de 1 a 4 .

Os valores médios de log de colesterol total, em mg/ $\mathrm{dL}$, revelaram que o grupo I $(1,78 \mathrm{mg} / \mathrm{dL})$ diferiu significativamente $(\mathrm{p}<0,05)$ dos grupos II $(2,66 \mathrm{mg} / \mathrm{dL})$, III (2,95 mg/dL) e IV (2,48 mg/dL). Não houve diferença estatística entre os grupos II $(2,66 \mathrm{mg} / \mathrm{dL})$, III $(2,95 \mathrm{mg} / \mathrm{dL})$ e IV $(2,48 \mathrm{mg} / \mathrm{dL})$ (Figura 1$)$.

Os valores médios de log de triacilgliceróis, em mg/ $\mathrm{dL}$, evidenciaram que o grupo I $(1,98 \mathrm{mg} / \mathrm{dL})$ diferiu significativamente $(\mathrm{p}<0,05)$ do grupo III $(3,0 \mathrm{mg} / \mathrm{dL})$, porém não diferiu dos grupos II $(2,81 \mathrm{mg} / \mathrm{dL})$ e IV (2,63 mg/dL). Os grupos II (2,81 mg/dL), III (3,0 mg/ $\mathrm{dL})$ e IV $(2,63 \mathrm{mg} / \mathrm{dL})$ não apresentaram diferenças estatísticas entre si (Figura 2).

Os valores médios de log de $\mathrm{HDL}$, em $\mathrm{mg} / \mathrm{dL}$, indicaram que o grupo I $(1,61 \mathrm{mg} / \mathrm{dL})$ diferiu significativamente $(\mathrm{p}<0,05)$ do grupo III $(2,55 \mathrm{mg} / \mathrm{dL})$, porém não diferiu dos grupos II (2,18 mg/dL) e IV (2,24 mg/ dL). Os grupos II (2,18 mg/dL), III (2,55 mg/dL) e IV $(2,24 \mathrm{mg} / \mathrm{dL})$ não apresentaram diferenças estatísticas entre si (Figura 3).

Os valores médios de log de LDL, em $\mathrm{mg} / \mathrm{dL}$, indicaram que o grupo I $(0,58 \mathrm{mg} / \mathrm{dL})$ diferiu signifi- cativamente $(p<0,05)$ dos grupos II $(1,80 \mathrm{mg} / \mathrm{dL})$, III $(2,18 \mathrm{mg} / \mathrm{dL})$ e IV $(1,76 \mathrm{mg} / \mathrm{dL})$. Não houve diferença estatística entre os grupos II (1,80 mg/dL), III $(2,18$ $\mathrm{mg} / \mathrm{dL})$ e IV (1,76 mg/dL) (Figura 4).

\section{Discussão e Conclusão}

De acordo com Levine e Saltzman ${ }^{5}$, estudos preliminares demonstraram que a administração do surfactante pelas vias subcutânea e intraperitoneal induziu inflamação no subcutâneo e no peritôneo, respectivamente, o que seria inadequado, especialmente em animais de experimento. Entretanto, Millar et al. ${ }^{7}$, constataram que a via intraperitoneal apresentou vantagens em relação à intravenosa por proporcionar maior facilidade e praticidade na administração sem a necessidade da utilização de anestesia geral, ausência de inflamação no local da aplicação ${ }^{10,14}$ e por apresentar índices reduzidos de falhas (5\%). Corroborando os achados de Millar et al. ${ }^{7}$, a aplicação do surfactante através da via intraperitoneal foi bem tolerada, de fácil contenção e manuseio dos animais experimentais, não sendo observado nenhum tipo de reação adversa durante todo o período experimental. A forma de administração por meio de aplicação intraperitoneal foi extremamente eficiente, pois não houve desperdício do princípio ativo, além de fácil contenção e manuseio por uma única pessoa. Os animais experimentais não apresentaram nenhuma evidência de inflamação no local da aplicação, através da inspeção macroscópica do peritôneo durante a necropsia, conforme os dados de Oliveira et al. ${ }^{14}$; Takahashi et al. ${ }^{10}$, além de não ter havido perda de animais durante todo o período experimental.

Bertges et al. ${ }^{20}$ ao avaliarem a qualidade e a durabilidade da hipercolesterolemia induzida pelo tyloxapol na dose de $200 \mathrm{mg} / \mathrm{kg}$ pela via intraperitoneal, descreveram o óbito de dez animais no $3^{\circ}, 6^{\circ}$ e $9^{\circ}$ dia após a administração do surfactante, o qual não foi evidenciado no atual trabalho com a dose de $500 \mathrm{mg} / \mathrm{kg}$ de 


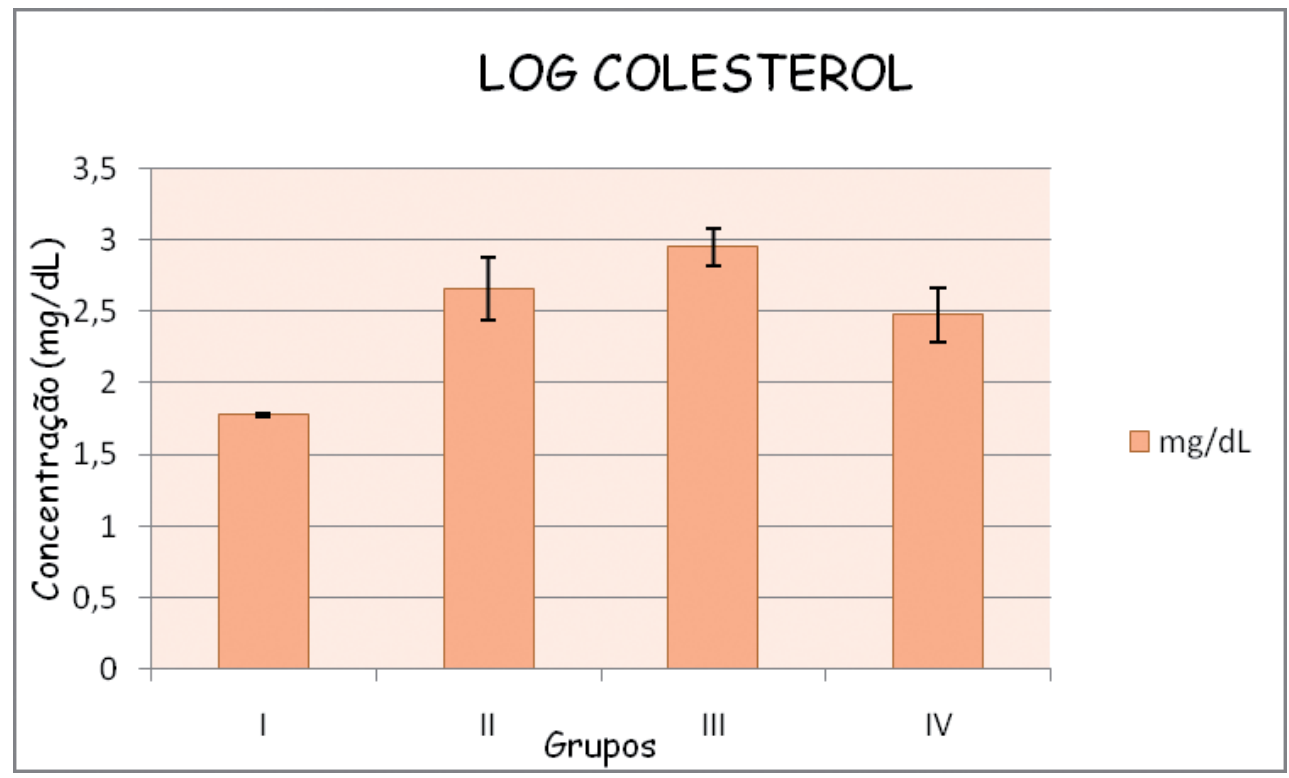

Figura 1 - Valores médios \pm EPM dos níveis séricos de Log de Colesterol Total, em mg/ $\mathrm{dL}$, de ratos Wistar, dos grupos controle (Grupo I), tratados com tyloxapol por duas semanas (Grupo II), tratados com tyloxapol por três semanas (Grupo III) e tratados com tyloxapol por quatro semanas (Grupo IV). Letras diferentes denotam significância $(\mathrm{p} \leq 0,05)$ pelo teste de Tukey (FCAV/Unesp - Jaboticabal/ SP - 2010)

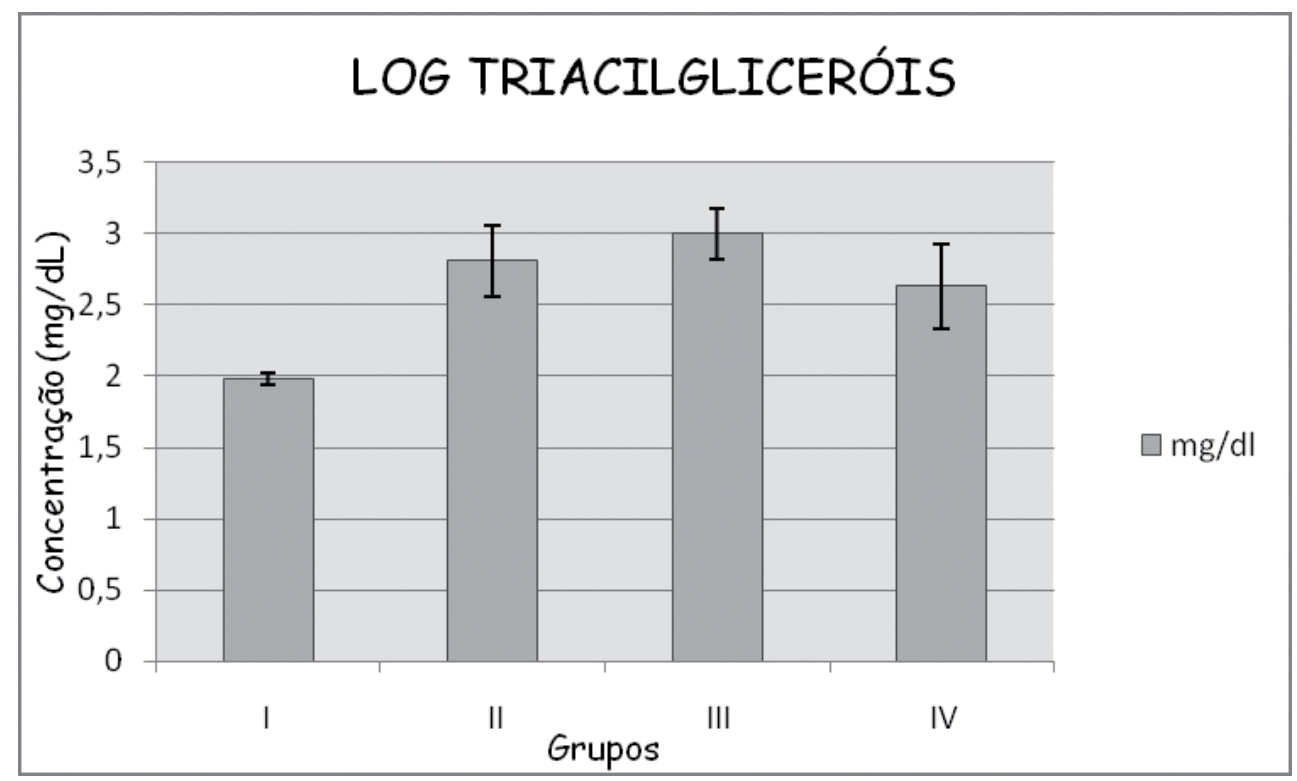

Figura 2 - Valores médios \pm EPM dos níveis séricos de Log de Triacilgliceróis, em mg/dL, de ratos Wistar, dos grupos controle (Grupo I), tratados com tyloxapol por duas semanas (Grupo II), tratados com tyloxapol por três semanas (Grupo III) e tratados com tyloxapol por quatro semanas (Grupo IV). Letras diferentes denotam significância $(\mathrm{p} \leq 0,05)$ pelo teste de Tukey (FCAV/Unesp - Jaboticabal/ SP - 2010) 


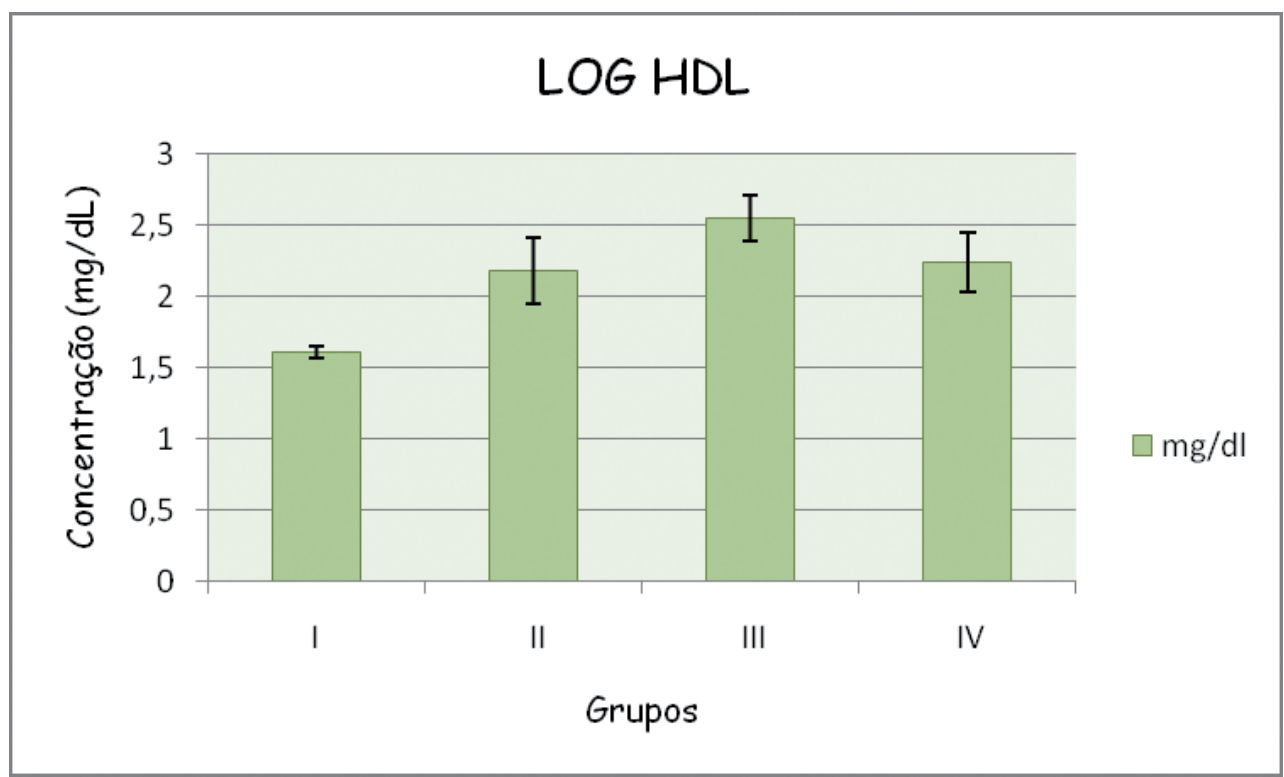

Figura 3 - Valores médios \pm EPM dos níveis séricos de Log de HDL, em mg/dL, de ratos Wistar, dos grupos controle (Grupo I), tratados com tyloxapol por duas semanas (Grupo II), tratados com tyloxapol por três semanas (Grupo III) e tratados com tyloxapol por quatro semanas (Grupo IV). Letras diferentes denotam significância $(\mathrm{p} \leq 0,05)$ pelo teste de Tukey (FCAV/Unesp - Jaboticabal/SP - 2010)

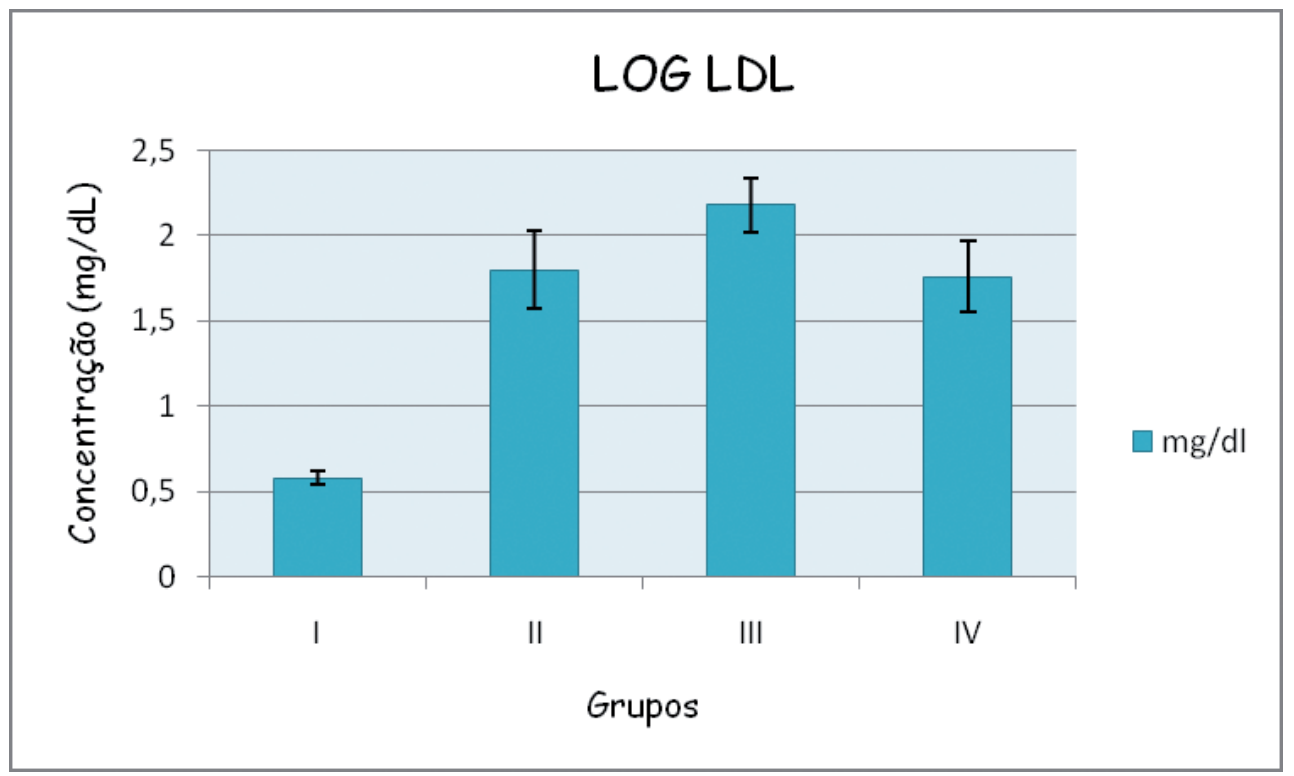

Figura 4 - Valores médios \pm EPM dos níveis séricos de Log de LDL, em mg/dL, de ratos Wistar, dos grupos controle (Grupo I), tratados com tyloxapol por duas semanas (Grupo II), tratados com tyloxapol por três semanas (Grupo III) e tratados com tyloxapol por quatro semanas (Grupo IV). Letras diferentes denotam significância $(\mathrm{p} \leq 0,05)$ pelo teste de Tukey (FCAV/Unesp - Jaboticabal/SP - 2010) 
peso corporal pela mesma via de administração. Tal fato pode ter ocorrido dada a realização de anestesias sucessivas para coleta de sangue no referido trabalho.

A dose do surfactante utilizada $(500 \mathrm{mg} / \mathrm{kg}$ de peso corporal) foi eficiente em elevar o perfil lipídico sérico e induzir lipemia intensa nos ratos estudados, concordando com Siddiqi et al. ${ }^{20}$ ao utilizarem a mesma dose na mesma espécie animal para indução de hipercolesterolemia e hipertriacilgiceridemia para estudo da atividade antihipertensiva e antidislipidêmica do extrato de folhas da Viola odorata. O que também reflete os achados de estudos prévios em que as doses de tyloxapol descritas para a mesma função estão em intervalos de 100 a $600 \mathrm{mg} / \mathrm{kg}$ de peso corporal a partir de uma solução previamente diluída com solução fisiológica a $10 \%$ 2,5,6,9,10,11,15,16,19,21,22.

Houve certa dificuldade na diluição prévia do surfactante em solução fisiológica para obtenção de uma solução a $10 \%$, já que o surfactante é extremamente oleoso. Desta forma, este procedimento foi realizado lentamente com homogeneização constante, o que não foi relatado em estudos anteriores.

Houve elevação acentuada das concentrações de colesterol, triacilgliceróis, LDL e HDL induzidos pelo surfactante neste experimento. Dietas suplementadas com óleos ou acrescidas de colesterol têm sido comumente utilizadas para indução da hiperlipidemia em ratos, entretanto, as concentrações obtidas nesse caso são menores comparadas às encontradas com a utilização do surfactante. De acordo com Morais et al. ${ }^{17}$, após 56 dias de suplementação dietética com óleos de soja, canola, azeite de oliva e gordura suína em níveis de $7 \%$ e $14 \%$, houve aumento nos valores de colesterol total, HDL e LDL+VLDL séricos quando a fonte foi gordura suína a $14 \%$, porém em níveis reduzidos comparados aos encontrados quando da utilização do surfactante nos animais aqui estudados.

Entretanto, a hipercolesterolemia induzida por Lima et al. ${ }^{13}$, em coelhos, utilizando-se ração acrescida de colesterol a $1 \%$ e ácido cólico $0,1 \%$, durante
28 dias, correspondeu a $1.590,40 \mathrm{mg} / \mathrm{dl} \pm 136,75$ e foi considerada proporcional aos valores obtidos nesse estudo com a utilização do surfactante.

Levine e Saltzman ${ }^{5}$ descreveram que uma única injeção intraperitoneal do surfactante na dose de $500 \mathrm{mg} /$ $\mathrm{kg}$ de peso corporal causou lipemia e induziu níveis elevados de colesterol, triacilgliceróis e HDL em ratos um e dois dias após a aplicação; e esses valores eram dez vezes ou mais elevados comparados ao grupo controle. Informações semelhantes foram obtidas por Obara et al. ${ }^{19}$, utilizando a dose de $250 \mathrm{mg} / \mathrm{kg}$ de peso corporal por via intravenosa do mesmo surfactante. Os valores obtidos foram elevados tanto de colesterol, como de triacilgliceróis, um e dois dias após a injeção do surfactante e estes retornaram ao normal no quarto dia após a utilização desta substância. Concordando com Levine e Saltzman ${ }^{5}$, Oliveira et al. ${ }^{16}$, Obara et al. ${ }^{19}$, constataram elevação dos níveis de colesterol, HDL e triacilgliceróis em ratos após 43 horas da administração do surfactante na dose de $300 \mathrm{mg} / \mathrm{kg}$ de peso corporal pela via intraperitoneal. Corroborando com Levine e Saltzman ${ }^{5}$, Oliveira et al. ${ }^{16}$, Obara et al. ${ }^{19}$,no presente estudo, após 48 horas da última administração do surfactante, foi evidenciada lipemia, mesmo após jejum alimentar de 16 horas, e elevação das concentrações de colesterol, triacilgliceróis, HDL e LDL 10 vezes mais intensa quando comparadas aos valores do grupo controle.

Levine e Saltzman ${ }^{5}$ demonstraram que, para obtenção de hipercolesterolemia e hipertriacilgliceridemia ininterruptas e persistentes (uma, duas e três semanas), foram necessárias três injeções do surfactante por semana, com intervalo de um ou dois dias entre elas. Assim, a hiperlipidemia foi mantida até três dias após a última injeção e a concentração de colesterol, nesse caso, foi 10 a 20 vezes maior quando comparada aos valores normais. No presente estudo, corroborando com os achados dos autores supracitados, as concentrações de colesterol evidenciadas 48 horas após a última injeção do surfactante foram 18 vezes mais elevadas que àquelas encontradas no grupo controle. 
Harnafi et al. ${ }^{2}$ descreveram que, após 7 e 24 horas da administração do surfactante na dose de $200 \mathrm{mg} /$ $\mathrm{kg}$ de peso corporal pela via intraperitoneal, houve marcante aumento dos valores de colesterol e triacilgliceróis, comparados ao grupo controle. Os valores séricos de colesterol total aumentaram 109\% e 270\%, respectivamente, comparados ao grupo controle e os valores de triacilgliceróis aumentaram mais que 20 e 12 vezes, respectivamente. No presente estudo, os valores de colesterol total, obtidos 48 horas após a última administração do surfactante na dose de 500 $\mathrm{mg} / \mathrm{kg}$ de peso corporal realizada em dias alternados durante três semanas, aumentaram de forma significativa, correspondendo a mais de 18 vezes (1745\%) comparados ao grupo controle. Quanto aos triacilgliceróis, os valores alcançados foram 14 vezes mais elevados comparados ao grupo controle.

Em relação ao HDL e LDL, Harnafi et al. ${ }^{2}$ perceberam que, 7 e 24 horas após a injeção do surfactante, os valores de $\mathrm{HDL}$ não alteraram e os valores de LDL aumentaram $328 \%$ e $653 \%$, comparados ao grupo controle. No presente estudo, 48 horas após a aplicação do surfactante, os valores de HDL elevaram-se $1006 \%$, diferindo então dos achados de Harnafi et al. ${ }^{2}$, e os valores de LDL elevaram $4236 \%$, comparados ao grupo controle.

Oliveira et al. $^{14}$, ao utilizarem o surfactante na dose de $300 \mathrm{mg} / \mathrm{kg}$ de peso corporal, por via intraperitoneal diluído em solução salina, perceberam a eficiência do mesmo na indução hiperlipidêmica nos animais estudados, com valores de $152,7 \%$ nos teores de colesterol total, 49,7\% de HDL e 108\% de triacilgliceróis 48 horas após a aplicação, comparados ao grupo controle. Concordando com o atual estudo que obteve uma elevação de $1745 \%$ e 1006\% nos níveis de colesterol total e HDL, respectivamente, comparados ao grupo controle.

Ao administrar o surfactante Tyloxapol na dose de $200 \mathrm{mg} / \mathrm{kg}$ por via intraperitoneal, Sunil et al. ${ }^{12}$ de- tectaram elevações plasmáticas do colesterol total, triacilgliceróis e LDL 18 horas após administração, entretanto, os valores plasmáticos de HDL apresentaram-se reduzidos, o que se opõe aos achados do atual estudo em que os níveis séricos de HDL mantiveramse elevados, comparados ao grupo controle, 48 horas após sua aplicação.

De acordo com Takahashi et al. ${ }^{10}$, o mesmo surfactante foi utilizado na dose de $400 \mathrm{mg} / \mathrm{kg}$ de peso corporal de ratos pela via intraperitoneal em uma solução previamente diluída a 10\% e foi efetivo na indução de hipercolesterolemia e hipertriacilgliceridemia ${ }^{18}$, além de induzir lipemia intensa. Tais resultados refletem os obtidos nesse estudo, porém, na dose de $500 \mathrm{mg} / \mathrm{kg}$ de peso corporal.

Houve diferença estatisticamente significativa de colesterol total e LDL entre o Grupo I (controle) e os demais grupos experimentais, comprovando, desta forma, uma elevação do perfil lipídico sérico com a utilização do surfactante Tyloxapol por até quatro semanas. Entretanto, houve diferença estatisticamente significativa nas concentrações detriacilgliceróis e HDL somente entre o Grupo I (controle) e o Grupo III (tratados por três semanas), provavelmente pelo fato de duas semanas de tratamento não terem sido suficientes para elevar de forma expressiva os níveis lipídicos séricos e, com quatro semanas de tratamento (Grupo IV), imagina-se que os animais já estavam adaptados para metabolizar o surfactante exógeno.

Desta forma, baseado nos resultados encontrados, sugere-se que o surfactante possa ser um agente indutor de hiperlipidemia. Porém,são necessários novos estudos com sua utilização a partir de quatro semanas e com o uso da microscopia eletrônica de varredura para verificar se há desenvolvimento de lesão aterosclerótica em arco aórtico a longo prazo, tornando, deste modo, a utilização do surfactante em ratos um padrão de modelo experimental para estudo da doença aterogênica. 


\section{Referências}

1. CHANDLER, C. E.; WILDER, D. E.; PETTINI, J. L.; SAVOY, Y. E.; PETRAS, S. F.; CHANG, G.; VINCENT, J.; HARWOOD, J. CP-346086: an MTP inhibitor that lowers plasma cholesterol and triglycerides in experimental animals and in humans. Journal of Lipid Research, v. 44, n. 10, p. 1887-1901, 2003.

2. HARNAFI, H.; BOUANANI, N. H.; AZIZ, M.; CAID, H. S.; GHALIM, N.; AMRANI, S. The hypolipidaemic activity of aqueous Erica multiflora flowers extract in Triton WR - 1339 induced hyperlipidaemic rats: A comparison with fenofibrate. Journal of Ethnopharmacology, v. 109, n. 1, p. 156-160, 2007.

3. CARVALHO, D. F.; PAIVA, A. A.; MELO, A. S. O.; RAMOS, A. T.; MEDEIROS, J. S.; MEDEIROS, C. C. M.; CARDOSO, M. A. A. Perfil lipídico e estado nutricional de adolescentes. Revista Brasileira de Epidemiologia, v. 10, n. 4, p. 491-498, 2007.

4.SPOSITO, A. C.; CARAMELli, B.; FONSECA, F. A. H.; BERTOLAMI, M. C. IV Diretriz brasileira sobre dislipidemias e prevenção da aterosclerose. Departamento de Aterosclerose da Sociedade Brasileira de Cardiologia. Arquivos Brasileiros de Cardiologia, v. 88, p. 01-19, 2007. Suplemento, 1.

5.LEVINE, S.; SALTZMAN, A. A procedure for inducing sustained hyperlipemia in rats by administration of a surfactant. Journal of Pharmacological and Toxicological Methods, v. 55, n. 2, p. 224-226, 2007.

6.PÉREZ, C.; CANAL, J. R.; ROMERO, A.; TORRES, M. D. Experimental hypertriglyceridaemia and hypercholesterolaemia in rats. Acta Physiologica Hungarica, v. 86, n. 1, p. 57-68, 1999.

7. MILLAR, J. S.; CROMLEY, D. A.; McGOY, M. G.; RADER, D. J.; BILLHEIMER, J. T. Determining hepatic triglyceride production in mice: comparison of poloxamer 407 and triton WR-1339. Journal of Lipid Research, v. 46, n. 1, p. 2023-2028, 2005.

8.SIDDIQI, H. S.; MEHMOOD, M. H.; REHMAN, N. U.; GILANI, A. H. Studies on the antihypertensive and antidyslipidemic activities of Viola odorata leaves extract. Lipids in Health and Disease, v. 11, n. 6, p. 1-12, 2012.

9. ABE, C.; IKEDA, S.; UCHIDA, T.; YAMASHITA, K.; ICHIKAWA, T. Triton WR1339, nainhiitor of lipoprotein lipase, decrease vitamin $\mathrm{E}$ concentration in some tissues of rats by inhibiting its transport to liver. The Journal of Nutrition, $\mathrm{v}$. 137, n. 2, p. 345-350, 2007.

10.TAKAHASHI, Y.; INABA, N.; KUWAHARA, S.; KUKI, W. CP-346086: an MTP inhibitor that lowers plasma cholesterol and triglycerides in experimental animals and in humans. Bioscience, Biotechnology and Biochemistry, v. 67, v. 11, p. 2448-2450, 2003.

11.WANG, Y. J.; SUN, J. B.; LI, F.; ZHANG, S. W. Hyperlipidemia intensifies cerulean-induced acute pancreatitis associated a with activation of protein kinase $\mathrm{C}$ in rats. World Journal of Gastroenterology, v. 12, n. 18, p. 2908-2913, 2006.
12.SUNIL, C.; IGNACIMUTHU, S.; KUMARAPPAN, C. Hypolipidemic activity of Symplocoscochinchinensis S. Moore leaves in hyperlipidemic rats. Journal Nature Medicine, v. 66, n. 1, p. 32-38, 2012.

13.LIMA, L. R. P.; OLIVEIRA, T. T.; NAGEM, T. J.; PINTO, A. S.; STRINGHETA, P. C.; TINOCO, A. L. A.; SILVA, J. F. Bixina, Norbixina e Quercetina e seus efeitos no metabolismo lipídico de coelhos. Brazilian Journal of Veterinary Research and Animal Science, v. 38, n. 4, p. 196-200, 2001.

14.OLIVEIRA, T. T.; GOMES, S. M.; NAGEM, T. J.; COSTA, N. M. B.; SECOM, P. R. Efeitos de diferentes doses de flavonóides em ratos hiperlipidêmicos. Revista de Nutrição, v. 15, n. 1, p. $45-51,2002 b$.

15.LIMA, L. R. P.; OLIVEIRA, T. T.; OLIVEIRA, M. G. A.; NAGEM, T. J.; PINTO, A. S.; GOMES, S. M.; SEIXAS FILHO, J. T. Determinação da atividade de lipase na presença de morina, naringenina, naringina e rutina. Ciência e Agrotecnologia, v. 23, n. 3, p. 626-631, 1999.

16. OLIVEIRA, T. T.; PEREIRA, W. L.; NAGEM, T. J.; PINTO, A. S.; SANTOS, C. A. Efeito regulatório de flavonóides e de carmin nos níveis de lipídeos em ratos Wistar. Arquivo Brasileiro de Medicina Veterinária e Zootecnia, v. 54, n. 1, p. 24-28, 2002.

17.MORAIS, C. S. N.; BARCELOS, M. F. P.; SOUSA, R. V.; LIMA, H. M.; LIMA, A. L. Efeitos das fontes e níveis de lipídios nas dietas de ratos machos da linhagem Wistar (Rattus norvegicus) sobre frações lipídicas do sangue. Ciência e Agrotecnologia, v. 27, n. 5, p. 1082-1088, 2003.

18. FIGUEIRA, T. R.; VERCESI, A. E.; OLIVEIRA, H. C. F. Lack of plasma albumin impairs intravascular lipolysis and explains the associated free fatty acids deficiency and hypertriglyceridemia. Lipids in Health and Disease,v. 9, n. 146, p. 1-6, 2010.

19.OBARA, K.; SAITO, T.; SHOJI, Y.; CHIBA, S.; SOMA, J.; SATO, H.; YOSHINAGA, K. Administration of Triton WR 1339 aggravates chronic aminonucleosidenephrosis. Nephron, v. 60, n. 1, p. 119-120, 1992.

20.BERTGES, L. C.; MOURÃO JUNIOR, C. A.; SOUZA, J. B.; CARDOSO, V. A. C. Hiperlipidemia induzida por Triton WR-1339 (Tyloxapol) em ratos Wistar. Revista Brasileira de Ciências Médicas e da Saúde, v. 1, n. 1, p. 29-31, 2011.

21.FAUTH, S.; SILVA, R. M.; SANTOS, F. A.; RAO, V. S. Atividade hipolipidêmica da trans-desidrocrotonina (T-DCTN), um diterpeno 19 nor-clerodano do crotoncajucarabenth (sacaca). Pesquisa Médica, v. 3, n. 1/4, p. 15-21, 2000.

22. OlIVA, M. E.; CHICCO, A. G.; FORTINO, M. A.; LOMBARDO, Y. B. Efectos de lasustitución de caseína por proteína de soja aislada como fuente proteica endislipemia experimental. Revista FABICIB, v. 12, p. 57-67, 2008. 